Alekh Verma, Aastha Narula, Akshi Katyal, Shakti Kumar Yadav, Priyanka Anand, Aarzoo Jahan, Sonam Kumar Pruthi, Namrata Sarin, Ruchika Gupta and Sompal Singh*

\title{
Failure rate prediction of equipment: can Weibull distribution be applied to automated hematology analyzers?
}

https://doi.org/10.1515/cclm-2018-0569

Received June 2, 2018; accepted July 6, 2018; previously published online August 8, 2018

\section{Abstract}

Background: Life cycle prediction measures, that provide information on the probability of failure of equipments, have been applied in electronic and mechanical engineering and for predicting the strength of dental implants. However, the same has not been utilized as yet in medical equipment such as hematology analyzers.

Methods: Failure data of five automated hematology analyzers (3-part differential) was collected over 14 consecutive months and a Weibull probability plot was made. The scale and shape parameters of this plot were used to predict failure probability distribution. This was then combined with various costs involved in remedial maintenance to get a cost analysis.

Results: The analyzers in their "useful life" period were found to suffer fewer actual and predicted failures compared to those in the "wear out" phase. Cost analysis showed a considerably higher per month cost of remedial maintenance of analyzers compared to the price of a comprehensive maintenance contract.

Conclusions: Our study demonstrates, for the first time, that Weibull distribution can be applied well to hematology analyzers for modeling of failure data and the resultant information is helpful in the cost analysis of maintenance to allow for prudent and informed decision making with regards to the mode of maintenance of analyzers.

Keywords: analyzer; failure rate; hematology; prediction; Weibull distribution.

*Corresponding author: Dr. Sompal Singh, MD, Department of Pathology, Hindu Rao Hospital, Malka Ganj, Delhi-110007, India, Phone:+91-9810873046, E-mail: sompal151074@gmail.com Alekh Verma, Aastha Narula, Akshi Katyal, Shakti Kumar Yadav, Priyanka Anand, Aarzoo Jahan, Sonam Kumar Pruthi and Namrata Sarin: Department of Pathology, Hindu Rao Hospital, Malka Ganj, Delhi, India

Ruchika Gupta: ICMR-National Institute of Cancer Prevention and Research, Noida, UP, India. http://orcid.org/0000-0003-0235-063X

\section{Introduction}

Automated analyzers, including hematology analyzers, have become vital components of medical laboratories over last few decades. Information with regards to the failure rate of equipment is an essential aspect of product engineering and its knowledge is important for the buyer at the time of purchase. For a product, life cycle prediction measures depend on a variety of factors such as the type and condition of the material used in the product, work load on the equipment, environmental factors and manner of use. Life cycle prediction has been widely used in electronic and mechanical engineering for a variety of purposes [1] However, the use of this important technical tool has been limited in medical science and has mainly been applied to prediction of the strength of dental implants [2,3]. Though the failure data for most of the components of an analyzer may be available to the engineers, these figures have been generated in controlled conditions and their behavior in 'far less controlled conditions' like a busy clinical laboratory has not been tested. An extensive literature search failed to yield any report of application of failure prediction measures to an analyzer in a clinical laboratory.

It has been shown that the probability of failure over the life of equipment usually follows a 'bath tub' pattern $[4,5]$ as depicted in Figure 1. Of all the three stages in this pattern, the period of "useful life" is of the most interest to the users of the equipment. The commonly used life cycle prediction measures include:

Failure rate $(\mathrm{FR})=\frac{\text { Number of failures }}{\text { Observation time } \times \text { Number of products }}$

Mean time between failures $(\mathrm{MTBF})=1 /$ Failure rate

MTBF of equipments (with components 1 to $\mathrm{n}$ )

$$
=\frac{1}{\text { FR1 }+ \text { FR2 }+ \text { FR } 3+\ldots . . . F R n}
$$

Mean time to repair $($ MTTR $)=\frac{\Sigma \text { Down time of repair }}{\text { Number of repairs }}$ 


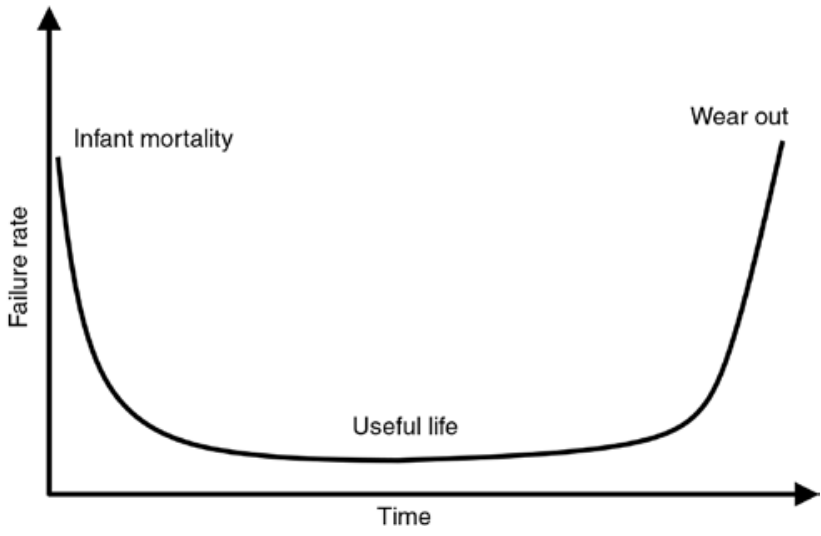

Figure 1: Depiction of failure rate over the lifetime of equipment.

$$
\text { Availability of equipment }=\frac{\text { MTBF }}{M T B F+M T T R}
$$

Of these formulae, mean time between failure (MTBF) is the most widely used life cycle prediction measure. The unit of this measure is usually related to either time frame (hours), distance (kilometers) or operating cycle (failure per 1000 cycles). As most of the equipment has many components, the MTBF of such equipment is calculated as the inverse of the summation of failure rates of individual components [6].

Equipment failure adversely affects the service to the customers due to reduced efficiency or service quality. Failure of equipment may be attributed to use for ill-suited purposes, failure of the user to maintain the equipment properly, a lack of skill of the user or because the equipment has reached the wear out phase. The probability of failure is usually quantitated by Weibull distribution. Weibull's 2-parameter distribution is shown in formulas 1 and 2 (formulae 1- 6 are given in the Appendix), where $F(t)$ is the cumulative density function (CDF) of distribution, which gives failure from time 0 to time $\mathrm{t}[7,8]$. The $\beta$ calculated from the Weibull distribution plot helps to classify the phase in the life cycle of the product: $\beta<1$ is seen in the infant mortality stage, $\beta=1$ for the useful life period and $\beta>1$ in the wear out phase.

The requirement of the maintenance of equipment varies depending on the phase of life cycle it is in at a particular time. Equipment maintenance can be divided into the following types: (a) Reactive maintenance, where equipment is fixed after a break down; (b) Preventive maintenance, which is done periodically in a planned manner; (c) Predictive maintenance using certain indicators that hint at impending breakdown; and (d) Pro-active maintenance (failure mode and effects analysis, FMEA) (http://www.uesystems.com/mechanical-inspection/ the-4-basic-maintenance-modes). In most laboratories, reactive maintenance is performed and this is usually cost-intensive. The cost of maintenance can be calculated using formula 3 (without preventive maintenance) and formula 4 (including preventive and remedial maintenance).

This study aims at assessing the applicability of Weibull's distribution plot for the prediction of failure rates of automated hematology analyzers in a clinical laboratory. In addition, cost analysis for maintenance of these analyzers has been attempted utilizing the data generated from the Weibull plot. To the best of our knowledge, this is the first study attempting the application of life cycle prediction measures to medical laboratory equipment.

\section{Materials and methods}

This was a prospective analysis including five automated hematology analyzers (three-part differential) installed in our laboratory. The manufacturer and model of all five analyzers were the same but have not been disclosed to avoid a conflict of interest. Of the five analyzers, three had been installed 2 years previously and hence were considered in the "useful life" period while two were in use for the previous 7 years and were considered to be in the "wear out" phase. For all the analyzers, data of equipment failure for 14 consecutive months was collected. The various reasons considered as equipment failure are tabulated in Table 1. Actual failure rates and the MTBF were calculated as per the formula given above. A Weibull probability plot was constructed using the failure data of the two groups: group A (useful life) and group B (wear out) and slope (for $\beta$ ) and intercept (for the MTBF) were calculated. Briefly, failure times of each analyzer were noted and arranged in ascending order to calculate the cumulative distribution function (CDF), as per formula 5 . This was followed by calculation of $\beta$ using formula 6 where $\log -\log [1 / 1-F(t)]$ and the $\log$ of failure times were plotted on a linear scale $[9,10]$. Further, statistical modeling was done utilizing 'Weibull distribution' with $\beta$ as obtained above to find the probabilities of machine failure over time for the two groups. These probabilities were, in turn, used for cost analyses of equipment maintenance.

Table 1: Situations considered as equipment failure for hematology analyzers in the present study.

Error in vacuum chamber or transducer assay

Shut down of equipment (not due to power outage)

White blood cell clog

Probe tilted

Problems in LCD/LED display

Differential leucocyte count not reported

Clamp not working

Probe breakdown

Motor not functional 


\section{Results}

During the 14-month observation time, the analyzers in group A had four failure episodes, compared to 28 for machines in group B. As group B comprised two analyzers, the average failure rate works out to be one per month. The model MTBF and actual MTBF are shown in Table 2. The MTBF is considerably longer for machines in group A. The Weibull probability plots for both the groups are shown in Figures 2 and 3.

\section{Costing of maintenance}

The cost analysis was based on the probabilities of machine failure over time. The expected failure probabilities revealed that only one analyzer will be functional at 11 months for group A. Hence, for machines in group A, a service engineer would need to visit once in 11 months while for analyzers in group B, breakdowns are expected to happen more frequently and an engineer would be required to visit every month. As the make and model of all five analyzers was the same in this study, the rate of a comprehensive maintenance contract (CMC at Rs. 45,000 per year), an engineer visit charge (Rs. 8000 per visit in absence of $\mathrm{CMC}$ ) and average remedial charges incurred in the event of failure (Rs. 50,000) were considered to be similar for both the groups. Using formulas 3 and 4, the remedial maintenance cost per month for the two groups was calculated. Analyzers in group A have fewer equipment failures and hence, per month maintenance cost worked out to be Rs. 9000. On the other hand, machines in group B fail almost every month with frequent engineer visits leading to a cost of Rs. 71,500 per month, which is much higher than the cost of CMC (Rs. 45,000 per year).

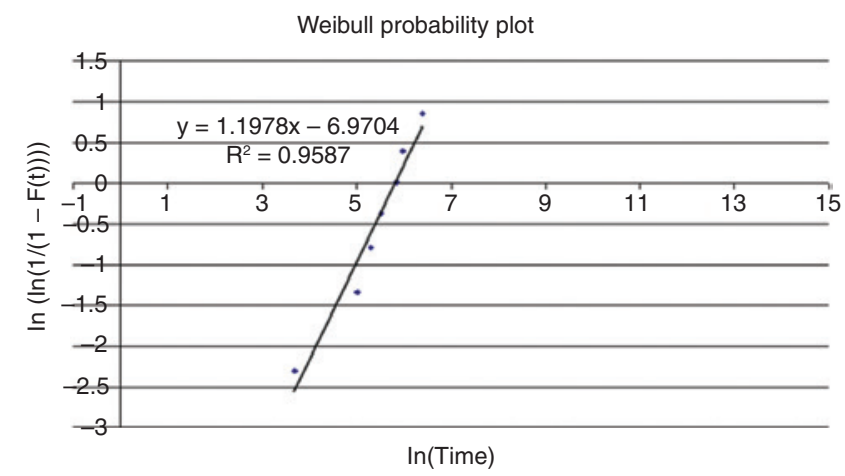

Figure 2: Weibull probability plot of hematology analyzers in the "useful life" phase in the present study.

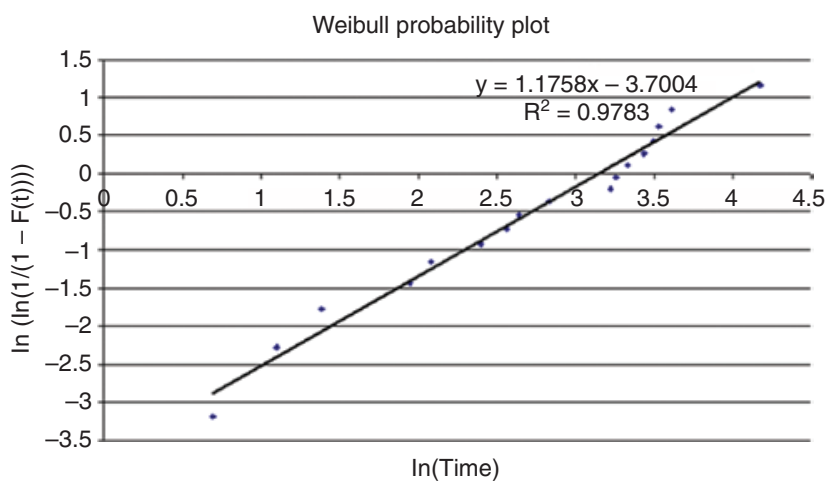

Figure 3: Plot of Weibull probability distribution of machines in the "wear out" phase.

\section{Discussion}

Hematology analyzers are an integral part of hematology laboratories for performance of cell counts, differential leukocyte analysis and additional parameters, depending on the version of the analyzer being used [11]. For efficient use of this equipment, failure and downtime have

Table 2: Modeling of prediction of failure and costing for the maintenance of equipment in the present study.

\begin{tabular}{|c|c|c|c|c|c|c|c|}
\hline & $\begin{array}{r}\text { Number of } \\
\text { machines }\end{array}$ & $\begin{array}{l}\text { Observation } \\
\text { period }\end{array}$ & $\begin{array}{r}\text { Failure } \\
\text { episodes }\end{array}$ & $\begin{array}{r}\text { Actual MTBF } \\
\text { (months) }\end{array}$ & $\begin{array}{r}\text { Failure rate } \\
\text { (per month) }\end{array}$ & Model $\beta$ & $\begin{array}{r}\text { Model } \\
\text { MTBF }\end{array}$ \\
\hline \multicolumn{8}{|l|}{ Modeling } \\
\hline Wear out & 2 & 14 months & 28 & 1 & 1 & 1.18 & 0.78 \\
\hline \multirow[t]{2}{*}{ Useful life period } & 3 & 14 months & 4 & 10.5 & 0.095 & 1.19 & 11.2 \\
\hline & \multicolumn{2}{|c|}{$\begin{array}{l}\text { Suggested } \\
\text { frequency of visit }\end{array}$} & $\begin{array}{l}\text { Remedial maintenance } \\
\text { ost (Rs. per month) }\end{array}$ & \multicolumn{2}{|c|}{$\begin{array}{l}\text { Visit charges / } \\
\text { machine (Rs.) }\end{array}$} & $\begin{array}{l}\text { CMC charg } \\
\text { (Rs. per ye }\end{array}$ & \\
\hline \multicolumn{8}{|l|}{ Costing } \\
\hline Wear out & \multicolumn{2}{|c|}{ Every month } & $1,500 /-(1041.40$ USD $)$ & \multicolumn{2}{|c|}{$8000 /-(116.52$ USD) } & \multicolumn{2}{|c|}{$45,000 /-(655.42$ USD) } \\
\hline Useful life period & \multicolumn{2}{|c|}{ Every 11 months } & $000 /-(131.09$ USD) & \multicolumn{2}{|c|}{$8000 /-(116.52$ USD) } & \multicolumn{2}{|c|}{$45,000 /-(655.42$ USD $)$} \\
\hline
\end{tabular}


to be kept to a minimum through maintenance, which is usually corrective or reactive in nature. A study by the World Health Organization (WHO) reported that nearly $50 \%$ of medical equipment in developing countries were not functioning properly due to a lack of effective maintenance policies [12].

Though the performance, productivity and effectiveness of engineering of medical equipment can be assessed using various benchmarks like CE (European Conformity) and others, life cycle prediction data for the majority of medical equipment, including hematology analyzers is currently not available from the manufacturers or the users. Life cycle prediction measures, that provide information on the probability of failure rate of a product, have been utilized in electronic engineering and for dental implants [2, 3]. Weibull distribution (2or 3-parameter) is the most representative method that can be used for the modeling of failure rates of mechanical components of a piece of equipment. This has two parameters: scale (time when $63.2 \%$ failures occur) and shape parameter [13]. Weibull distribution is considered to be the most robust system as special types of Weibull distribution with shape parameter 2 and scale parameter $\eta \sqrt{2}$ attains similarity to Rayleigh distribution, that with shape parameter 1 and scale parameter $\eta$ becomes an exponential distribution, whereas that with a shape parameter 3.25 and scale parameter $\eta$ becomes normal distribution [8]. Weibull distribution has been studied for deformation behavior of bulk metallic glass composites. Jiang concluded that the statistical model based on Weibull distribution successfully predicted composite yield strength, deformation and elongation [2]. For resin based materials used in computer-aided design and manufacture (CAD/CAM) restorations, Lim et al. studied reliability, failure probability and strength and were able to calculate flexural strength of $5 \%$ fracture probability [3]. Similarly, a systematic review of the Weibull statistics for reporting the strength of dental materials by Quinn and Quinn concluded that Weibull analysis, with its strong theoretical basis, is of potential value for this purpose [14]. However, an extensive literature search failed to yield any report of the application of Weibull distribution for the prediction of failure rate of medical equipment like automated hematology analyzers.

For equipment like analyzers, adequate data on clinical precision, accuracy and linearity, i.e. quality parameters are usually available with the manufacturer to guide the potential buyer. However, a lack of validated data on the prediction of failure rate such as the MTBF with the manufacturer of the equipment leaves the buyer in a precarious position on the aspect of the potential useful life of the equipment and the cost of maintenance likely to be incurred during use of the analyzer. Our study shows, for the first time, a significant difference in the MTBF between the hematology analyzers in the "useful life" period and the "wear out" phase. As the model $\beta$ of group A in our study was $>1$, the analyzers may actually be in the wear out phase. However, the MTBF of group A was still much longer than group B, as the MTBF predicts the probability of equipment failure when applied to a group of similar equipment. Though the MTBF cannot predict the failure of a particular analyzer accurately, the failure prediction model may be incorporated into the intelligent dashboard of a laboratory information system for the real time monitoring of equipments [15]. This, however, requires further study.

As the majority of the equipment buyers are partly cost-driven, an interest in the potential maintenance cost of an analyzer during its life is obvious. We have demonstrated the utility of parameters calculated from Weibull's distribution for cost analysis of the maintenance of hematology analyzers. In our study, the remedial maintenance cost of analyzers in the 'wear out' phase was much higher than the annual cost of CMC and hence, a comprehensive maintenance contract seems prudent to go for such equipment. Such cost analysis, when performed correctly, can also be helpful in making decisions about when to phase out equipment and invest in a new one in its place.

Hence, to conclude, our study demonstrates for the first time the application of Weibull distribution to calculate the probability of failure and the MTBF of clinical laboratory equipment like analyzers along with the use of these parameters in maintenance cost analysis. This data is potentially useful for informed decision making regarding the mode of maintenance of these equipments in a laboratory. Further studies assessing this application for other analyzers are required to ensure the wider acceptance of Weibull distribution in laboratory equipment.

Author contributions: All the authors have accepted responsibility for the entire content of this submitted manuscript and approved submission.

Research funding: None declared.

Employment or leadership: None declared. Honorarium: None declared.

Competing interests: The funding organization(s) played no role in the study design; in the collection, analysis, and interpretation of data; in the writing of the report; or in the decision to submit the report for publication. 


\section{Appendix: Formulae}

\section{Formulae 1 and 2}

$$
\begin{gathered}
F(t)=1-\exp \left(-\frac{t}{\eta}\right)^{\beta} \\
R(t)=\exp \left(-\frac{t}{\eta}\right)^{\beta}
\end{gathered}
$$

where

' $t$ ' = Failure time

$\eta=$ characteristic life or scale factor

$\beta=$ shape parameter

\section{Formula 3}

$$
T c=\frac{N \times C_{R M}}{\mathrm{MTBF}}
$$

\section{Formula 4}

$$
\begin{gathered}
\text { Cost }(t)=N \times C_{P M}+B(t) \times C_{R M} \\
B_{t}=N \sum_{i=1}^{t} P_{i}+\sum_{i=1}^{t-1} \beta_{t-i} \times P_{i}
\end{gathered}
$$

$N=$ Number of machines

$C_{P M}=$ Cost of preventive maintenance per episode

$C_{R M}=$ Cost of remedial maintenance per episode

\section{Formula 5}

$$
F\left(t_{i}\right)=\frac{(i-0.3)}{(n+0.4)}
$$

\section{Formula 6}

$$
\ln \ln \left(\frac{1}{1-F(t)}\right)=\beta \ln t-\beta \ln \eta
$$

\section{References}

1. Li X, Lu WF, Zhai L, Er MJ, Pan Y. Predictive modeling for life cycle reliability analysis and machine health condition prediction in remanufacturing. In: Nee A, editor. Handbook of Manufacturing Engineering and Technology. London: Springer, 2014.

2. Jiang Y. Mesoscopic constitutive model for predicting failure of bulk metallic glass composites based on the free-volume model. Materials (Basel) 2018;11:327.

3. Lim K, Yap AU, Agarwalla SV, Tan KB, Rosa V. Reliability, failure probability, and strength of resin-based materials for CAD/CAM restorations. J Appl Oral Sci 2016;24:447-52.

4. Peng C, Liu G, Wang L. Piecewise modeling and parameter estimation of repairable system failure rate. Springerplus 2016;5:1477.

5. Bebbington $M$, Lai CD, Zitikis R. Modeling human mortality using mixtures of bathtub shaped failure distributions. J Theor Biol 2007;245:528-38.

6. Stanley S. MTBF, MTTR, MTTF \& FIT: explanation of terms. Available at: http://www.bb-elec.com/Learning-Center/All-WhitePapers/Fiber/MTBF,-MTTR,-MTTF,-FIT-Explanation-of-Terms/ MTBF-MTTR-MTTF-FIT-10262012-pdf.pdf. Accessed: 24 May 2018.

7. Billinton R, Allan RN. Reliability evaluation of engineering systems: concept and Techniques. Boston: Pitman Books Limited, 1983.

8. Abernethy RB. The new Weibull Handbook, 4th ed. North Palm Beach, FL, USA: Robert B. Abernethy, 2003. ISBN 0-9653062-1-6.

9. Ahmad R, Kamaruddin S, Mokthar M, Almanar IP. Identifying the best fit failure distribution and the parameters of machine's component: a new approach. Proceedings of International Conference on Man-Machine Systems, Langkawi, Malaysia, 2006.

10. Nelson W, Thompson VC. Weibull probability papers. J Qual Technol 1971;3:140-6.

11. Chhabra G. Automated hematology analyzers: recent trends and applications. J Lab Physicians 2018;10:15-6.

12. WHO Regional Committee for the Eastern Mediterranean. June 2016. "The role of medical devices and equipment in contemporary health care systems and services".

13. Hriber L. "Software component quality prediction in the legacy product development environment using Weibull and other mathematical distributions". International Conference on Software, Telecommunications and Computer Networks, SoftCOM 2009.

14. Quinn JB, Quinn GD. A practical and systematic review of Weibull statistics for reporting strengths of dental materials. Dent Mater Off Publ Acad Dent Mater 2010;26:135-47.

15. Azadmanjir Z, Torabi M, Safdari R, Bayat M, Golmahi F. A map for clinical laboratories management indicators in the intelligent dashboard. Acta Inform Med 2015;23:210-4. 